\title{
INSTITUIÇÕES E CONFLITOS COMERCIAIS NO MERCOSUL
}

\author{
Tullo Vigevani \\ Marcelo Passini Mariano \\ Ricardo Glöe Mendes
}

\begin{abstract}
Resumo: De que forma a evolução da estrutura institucional do Mercosul, desde sua criação até sua atual conformação, facilita a transformação de conflitos econômico-comerciais, de menor e maior grau, em conflitos políticos. Acredita-se que uma parte significativa dos conflitos no Mercosul poderia ser solucionada tecnicamente, sem resvalar nas relações políticas globais dos Estados membros, como tem ocorrido regularmente. Palavras-chave: integração regional; instituições; Mercosul.
\end{abstract}

Abstract: How, since its creation, has the evolving institutional structure of Mercosul helped turn economic and trade disagreements of varying magnitudes into political conflicts? It is believed that a significant portion of the disagreements within Mercosul could be solved at the technical level, without becoming the basis of foreign policy rifts, as is often the case.

Key words: regional integration; institutions; Mercosul.

$\mathrm{T}$ endo em vista o recrudescimento dos conflitos comerciais e políticos entre os Estados membros do Mercosul nos últimos anos, principalmente entre a Argentina e o Brasil, o tema de uma alteração na sua estrutura institucional volta à tona. A recente declaração do Presidente Fernando Henrique Cardoso, ${ }^{1}$ sobre a possibilidade do bloco adotar órgãos supranacionais, pode ser vista por esta ótica, pois demonstra, ainda que de forma tênue, que existe uma preocupação em melhorar a forma como a estrutura institucional do Mercosul soluciona os conflitos intra-regionais.

Analisando a evolução desse processo, vê-se que a estruturação institucional da integração no Cone Sul começou já em 1985, com a Declaração de Iguaçu, durante os governos Alfonsín e Sarney, tendo como elemento dinamizador uma articulação estatal-burocrática binacional liderada pelo Itamaraty e o Palácio San Martin, contando com o auxílio de setores dos Ministérios da Economia e Bancos Centrais.

Em 1986, com a assinatura do Programa de Integração e Cooperação Econômica (PICE), esse núcleo decisório fortaleceu-se e iniciou o estabelecimento de uma estrutura institucional de caráter intergovernamental. Ao mesmo tempo, os primeiros resultados econômicos da integração e a visualização das possibilidades comerciais despertaram o interesse do empresariado.

Nesse período, a participação dos setores não-governamentais ainda era dificultada pela ausência de canais apropriados, o que só ocorreria mais tarde, durante a fase de transição do Mercosul. Uma possível explicação para essa limitação da participação do setor privado era a forte instabilidade política e econômica nos dois países, gerando no âmbito nacional incerteza quanto à viabilidade de um processo de integração entre esses Estados, e, de certa forma, desviando as atenções dos grupos de interesse organizados para as questões internas imediatas.

\section{A INSTITUCIONALIZAÇÃO DO MERCOSUL}

A intenção de formar um mercado comum surgiu somente em 1988, com o Tratado de Integração, Cooperação e Desenvolvimento entre Argentina e Brasil. Apesar da evolução nas intenções para aprofundar a integração, com a criação de uma Comissão Parlamentar e um maior entrelaçamento entre os temas domésticos e os externos, a estrutura ainda dificultava a relação com setores não- 
governamentais. O principal agravante era a situação macroeconômica nos dois países, que induzia a uma centralização ainda maior da coordenação da integração nos Ministérios das Relações Exteriores, resultante da preocupação com o agravamento da situação interna que cada vez mais exigia a atenção dos governantes e dos ministérios envolvidos com esse processo.

Foi com o Tratado de Assunção, em 1991, que a integração passou a ser o ponto mais dinâmico e fundamental das diplomacias dos países envolvidos, revitalizando a vontade política dos governantes em aprofundar a integração no Cone Sul, ao mesmo tempo que havia ampliação e melhoria nos mecanismos decisórios.

Além das burocracias envolvidas e do espaço já existente para os Parlamentos nacionais, surgiram canais de participação dos setores não-governamentais, englobando não só o empresariado, mas também os representantes dos trabalhadores. Foi no interior dos Subgrupos de Trabalho (SGTs) do Grupo Mercado Comum (GMC) que essa participação se efetivou.

Nesse período, o centro decisório ainda estava concentrado nos Ministérios das Relações Exteriores, havia uma forte dependência da vontade política dos governantes, o Conselho do Mercado Comum (CMC) era o único órgão a produzir decisões e os canais de participação dos atores não-governamentais estavam localizados apenas nos Subgrupos de Trabalho, que produziam recomendações ao GMC e, portanto, formalmente não tinham poder decisório, mas influenciavam os rumos que tomavam as questões técnicas.

Apesar de a estrutura institucional apresentar tais entraves à participação dos setores não-governamentais, cujo interesse em influenciar os destinos da integração mostrou-se importante, tanto que formas alternativas de articulação foram implementadas no próprio aparelho institucional e também fora dele, no âmbito regional. Exemplo disso foi a forte pressão dos setores sindicais para a formação do Subgrupo 11, que não era previsto ao tempo da assinatura do Tratado de Assunção.

Durante o período de transição (anterior ao Protocolo de Ouro Preto) ficou evidente o peso político dos formuladores iniciais. A articulação bem-sucedida entre as burocracias argentina e brasileira ligadas à política exterior conseguiu, na medida do possível, firmar sua posição de defesa de uma estrutura intergovernamental.

É possível perceber esse aspecto ao se analisarem as negociações travadas no interior do Grupo Ad Hoc sobre Aspectos Institucionais, que discutia a evolução institu- cional para depois do período de transição. O acordo referente aos temas de intergovernamentalidade, supranacionalidade e sistemas decisórios permitiu visualizar como os interesses dos países estavam distribuídos. Argentina e Brasil apresentaram-se favoráveis a uma alteração no sistema decisório atual caracterizado pelo consenso e por uma manutenção da estrutura institucional intergovernamental, não supranacional. Isso permitiria que a força política dos formuladores iniciais fosse mantida, tendo um maior controle do processo integracionista. Já o Paraguai e o Uruguai mostraram interesse, inerente às suas realidades, em manter o sistema decisório por consenso a fim de sustentar seu relativo poder de veto. Ao mesmo tempo, eram favoráveis à conformação de instituições supranacionais, pois supunham que isto seria benéfico nos casos de solução de controvérsias e conflitos de interesses governamentais, ao diminuir os impactos que o peso argentino e brasileiro representam para eles.

O resultado final foi a manutenção do sistema decisório por consenso e da estrutura institucional intergovernamental. Isso permite dizer que esses dois grupos de países acordaram em uma concessão mútua: enquanto os dois maiores países aceitaram manter a regra do consenso, os dois menores renunciaram a sua posição em torno de instituições com caráter supranacional. Dessa forma, a cooperação entre eles garantiu ganhos para todos e adiou a definição da conformação institucional do Mercado Comum.

Nesse contexto, o Protocolo de Ouro Preto resultou numa estrutura institucional mais ramificada, com atribuições mais bem definidas e com mecanismos mais específicos para a atuação dos setores não-governamentais através da constituição do Fórum Consultivo Econômico e Social (FCES). No entanto, o poder decisório manteve-se com as burocracias governamentais formuladoras das políticas externas.

Quanto às decisões, estas sofreram uma ampliação na sua origem e no seu alcance. Agora, não só o CMC é o órgão decisório, como também o GMC e a Comissão de Comércio do Mercosul, produzindo normas obrigatórias aos Estados participantes.

\section{Atores e Demandas}

A estrutura institucional do Mercosul é constituída por órgãos e mecanismos decisórios que prevêem a atuação dos seguintes atores: a burocracia governamental, os atores não-governamentais e os partidos políticos. 
Os atores governamentais são a base do Mercosul e estão presentes em quase todos os seus órgãos. A proveniência de um membro governamental no Mercosul marca a sua atuação, isto é, membros que coordenam ou decidem têm origem obrigatória nos Ministérios de Relações Exteriores, da Economia e Bancos Centrais, enquanto aqueles que participam da análise e negociação decisórias, tendo uma atuação mais consultiva, podem ser oriundos destes e de outros ministérios dos governos envolvidos, conforme a necessidade técnica dos temas tratados.

No caso dos governantes pode haver a oportunidade de conjugar liderança pessoal, sentido de oportunidade econômica e necessidade de projeção internacional (Hirst, 1995), utilizando a integração como projeto mais de governo do que de Estado, o que significa que tendem a possuir uma visão de curto e médio prazos, associada quase que especificamente à duração de seus mandatos.

As burocracias governamentais ligadas à definição das políticas econômicas acabaram por desenvolver corpos técnicos apropriados à problemática da integração, além de fazer com que o comércio exterior e a política regional passassem a ter uma relevância maior para a definição das políticas domésticas.

Os atores não-governamentais, ou setor privado, como é definido pelos acordos de integração no Mercosul, são o setor empresarial, sindical, organizações não-governamentais de interesse específico (ONGs ambientais, direitos do consumidor, direitos humanos, etc.) e movimentos sociais.

Os setores empresarial e sindical são os atores nãogovernamentais mais atuantes no processo de integração do Cone Sul, principalmente pelo fato de que os outros atores apenas tiveram sua participação prevista na estrutura institucional após a criação do Fórum Consultivo Econômico e Social (FCES) criado pelo Protocolo de Ouro Preto, no final de 1994.

Os mecanismos de participação social desenvolveramse de forma insuficiente, se comparados com a sua importância para o processo. O setor privado sempre teve caráter consultivo dentro da estrutura institucional do período de transição, mas com o Protocolo de Ouro Preto pôde contar com um órgão específico para sua atuação - o Fórum Consultivo Econômico e Social -, abrindo uma oportunidade para a inclusão de setores que extrapolassem a esfera do capital e do trabalho.

É importante notar que mesmo um ano depois da criação do FCES, ainda havia uma preferência em dar prioridade a canais informais de pressões ou a práticas de lobby já desenvolvidas no âmbito nacional (Hirst, 1995). Pode- se concluir que isso ocorreu em virtude dos canais institucionalizados com poder consultivo serem insuficientes para um posicionamento mais ativo, privilegiando o acompanhamento técnico da evolução do processo. Questões políticas e comerciais mais pontuais, que necessitavam de uma resposta rápida, tenderiam a ser levadas diretamente à burocracia decisória, aos governos nacionais ou às chancelarias. No Mercosul, os canais pelos quais a atuação dos setores não-governamentais ocorre são estreitos, não permitindo atender a uma demanda que necessite de uma tramitação mais veloz.

Esse aspecto é agravado pelo caráter intergovernamental do processo, pelo fraco interesse demostrado pelos Parlamentos nacionais e pela inexistência de um Tribunal ou Corpo de Justiça dedicado à solução de problemas e de conflitos no interior do Mercosul, levando à conclusão que o diálogo político se dá mais entre a sociedade e o governo do que entre a sociedade e os órgãos do Mercosul.

É interessante ressaltar que, no caso brasileiro, a prática de negociação nos assuntos que ultrapassam as fronteiras do Estado Nacional conta com a quase exclusiva participação do Itamaraty e a ausência de setores sociais diversos, assim como o escasso espaço para a discussão com a comunidade acadêmica, diferente do que acontece em países com posicionamento externo mais atuante (Tomassini, 1988). Isso resulta principalmente das características próprias do Itamaraty que, na condição de organismo estatal voltado para a formação de quadros especializados nos assuntos internacionais, tem conseguido manter sua preeminência nas decisões de política externa.

A estrutura institucional do Mercosul tem atribuído ao sistema representativo um caráter apenas consultivo, com o objetivo único de facilitar a tramitação das decisões adotadas regionalmente no interior dos sistemas legislativos nacionais. A intergovernamentalidade do processo faz com que as normas emanadas pelos órgãos decisórios sejam obrigatórias para os Estados-partes, embora tenham de se adequar e ser incorporadas ao sistema de leis de cada país. Dessa forma, a Comissão Parlamentar Conjunta (CPC) tornou-se um órgão intermediário entre o centro decisório do Mercosul e os Parlamentos nacionais, sem caráter propositivo e com um poder de atuação que, no limite, poderia apenas dificultar a aprovação das normas do Mercosul.

Esse papel facilitador da CPC combinou perfeitamente com a estratégia da burocracia integracionista, no período de transição, de avançar pelo mais fácil. Segundo Nye (1994), esse tipo de postura pode ser entendido pelo conceito de integração negativa, isto é, quando os custos vi- 
síveis são baixos nos primeiros passos da integração é mais fácil conseguir concordância, no entanto, a integração de baixo custo e procedimentos decisórios de estilo tecnocrático tem menor durabilidade e não chega a um amplo apoio popular, dificultanto a legitimação do processo.

Os partidos políticos têm tido uma participação marginal, seus vínculos com órgãos técnicos do Mercosul têm sido informais e inconstantes, o que resultou numa mobilização parlamentar limitada, e por vezes desarticulada. Além disso, os partidos não contam com redes interpartidárias que promovam práticas interativas na região. Também não existe um parentesco ideológico e programático que estimule esse tipo de integração, pois cada país tem uma estrutura partidária própria, sem correspondência política e ideológica (Mariano, 2001).

Conclui-se, assim, que a estrutura institucional e as características políticas dos países do Mercosul não permitiram um papel mais relevante às organizações político-partidárias. Estas últimas tampouco se empenharam para firmar posição e alcançar um posicionamento adequado à sua importância para o desenvolvimento da integração regional.

É importante ressaltar que apesar do Mercosul mostrar-se como um processo dinâmico, não se pode concluir, com base nesta característica, que as possibilidades de estagnação ou retrocesso estão afastadas. Pelo contrário, a evolução institucional ainda tem um longo caminho a percorrer a fim de alcançar um patamar de maior previsibilidade e continuidade.

\section{O SISTEMA DE SOLUÇÃO DE CONTROVÉRSIAS}

O Tratado de Assunção previa, desde o início, um mecanismo provisório de resolução de controvérsias. ${ }^{2}$ Em sua primeira reunião de presidentes, ${ }^{3}$ o CMC emitiu sua Decisão ${ }^{\circ}{ }^{1}$, adotando o Protocolo de Brasília para a Solução de Controvérsias durante o processo de transição. Esse protocolo era provisório, mas acabou sendo institucionalizado pelo Protocolo de Ouro Preto, junto com o restante da estrutura orgânica do Mercosul no período pós-transição.

O Protocolo de Brasília procurou sanar as principais deficiências do Anexo III do Tratado de Assunção. Sua aplicação compreende as controvérsias que possam ocorrer sobre (art. 1): a interpretação, aplicação e falta de cumprimento das normas originais e derivadas.

As fontes do ordenamento jurídico do Mercosul são normalmente divididas pelos juristas em originais e deri- vadas. As originais se constituem do Tratado de Assunção e acordos celebrados no âmbito do mesmo; as decisões do CMC e resoluções do GMC são as fontes derivadas. O protocolo reconhece dois procedimentos distintos, dependendo de quem lhes dá início, um Estado-parte ou um particular.

A possibilidade do particular acionar o sistema de solução de controvérsias constitui importante inovação em relação ao Anexo III, que não previa esta possibilidade, embora com limitações.

Em primeiro lugar, vejamos o procedimento adotado quando a controvérsia se faz entre Estados membros do Mercosul. As partes em conflito devem procurar, antes de tudo, resolver a controvérsia através da negociação direta. As únicas exigências nessa primeira fase são que o GMC seja informado, por meio da Secretaria Administrativa, sobre a evolução do processo e sua resolução, caso houver, e que as negociações tenham o limite máximo de 15 dias (art. 3). Se não for possível obter um acordo nessa primeira fase, qualquer dos Estados envolvidos pode submeter a controvérsia ao GMC, que, após devida apreciação, com ou sem assessoria técnica de um painel de especialistas, formulará as recomendações aos Estados litigantes (art. 5). Essa fase deve durar 30 dias a partir da data de comunicação da questão à Secretaria Administrativa do Mercosul.

Se ainda persistir a divergência entres os Estados, mesmo após as recomendações do GMC, inicia-se o procedimento arbitral, que começa quando um governo insatisfeito com a solução apresentada pelo GMC comunica à Secretaria Administrativa sua intenção de recorrer ao referido procedimento. Esta, por sua vez, comunica tal ocorrência aos demais envolvidos e ao GMC, que se encarregará da tramitação da questão.

Primeiro, ocorre a formação de um Tribunal Arbitral para solucionar a questão. A controvérsia deve ser resolvida dentro de 60 dias, prorrogáveis por mais 30, por decisão da maioria dos árbitros. A decisão se expressa através de uma lauda, obrigatória para o Estado infrator, sem possibilidade de impugnação. A partir do recebimento da lauda, o infrator deve cumprir suas determinações num prazo de 15 dias. Caso o governo não cumpra em 30 dias, o país prejudicado pode adotar medidas compensatórias até que a decisão do Tribunal seja cumprida. Entretanto, as laudas não usufruem de execução forçada, ou seja, dependem da cooperação jurídica dos Estados para se fazerem cumprir.

Quanto ao procedimento adotado no caso de particulares, este se inicia com o exame da reclamação pela Seção Nacional do GMC onde o reclamante reside ou tenha sede 
de negócios (art. 26). Oteiza (1992) afirma que tal procedimento consiste simplesmente em: "una simple denuncia de violación del derecho aplicable por el Tratado de Asunción y sus normas derivadas. Los Estados se reservan indirectamente, mediante el control de admisibilidad ejercido por el Grupo derecho a rechazar la petición de los particulares. Es claro el dominio que los Estados tienen sobre el Grupo Mercado Común, que es coordinado por el Ministerio de Relaciones Exteriores de cuatro Estados, que lleva a pensar que esta vía de acceso a los intentos de solución de controversias constituye simplemente el derecho de personas de sugerir que se contemple determinada situación." De fato, pode-se afirmar que o acesso de particulares ao sistema de solução de controvérsias permanece limitado, considerando essas peculiaridades de acesso.

A única participação do particular no trâmite da questão se restringe ao fornecimento dos elementos necessários à Seção Nacional para determinar se há violação ou ameaça de prejuízo. Violação é definida como a sanção ou aplicação de medidas legais ou administrativas de efeito restritivo, discriminatório, ou de concorrência desleal, em desacordo com o Tratado de Assunção e acordos celebrados em seu âmbito, bem como das decisões do CMC e do GMC (art. 25).

Uma vez detectada a violação ou ameaça de prejuízo, a Seção Nacional do GMC pode entrar em contato com a Seção Nacional do CMC do Estado a quem se atribui a violação, para tentar uma solução imediata para a questão, ou submetê-la diretamente ao CMC, no caso em que o contato com a Seção Nacional do governo infrator não produzir resultados dentro de 15 dias após o seu início. Já nas mãos do GMC, este avaliará a validade da questão, podendo rejeitá-la ou não. Aceitando-se a reclamação, ocorrerá a convocação de um grupo de especialistas para emitir um parecer dentro de 30 dias após sua formação. $\mathrm{O}$ particular e o Estado a quem se atribui a violação terão oportunidade de ser consultados durante este período.

O Protocolo de Ouro Preto, no qual supostamente deveria ter sido incluída a criação de um mecanismo de solução de controvérsias definitivo, em oposição à transitoriedade do Protocolo de Brasília, pouco veio a acrescentar. Decidiu-se, em Ouro Preto, atribuir à recém-criada CCM o papel de examinar as reclamações feitas pelos Estados integrantes, a qual ganhou papel relevante na solução de disputas, tornando-se órgão competente para tratar dos conflitos comerciais em primeira instância. Com poder de emitir apenas recomendações, igual ao GMC, a CCM pode decidir imediatamente sobre a questão ou formar um comitê técnico com 30 dias para emitir parecer. O Estado, objeto de reclamação, deve cumprir o determinado no prazo estipulado.

O GMC passou a ter jurisdição quando: 1) não se obtém sucesso na fase de negociações diretas; 2) a controvérsia foi solucionada de forma parcial pelos Estados litigantes e, ao ser enviada à CCM, esta não pode efetivamente solucioná-la.

Em suma, a estrutura intergovernamental do bloco consolidou um sistema de resolução de disputas no qual prevalece a negociação diplomática e política, buscando sempre um acordo entre as partes antes de recorrer ao procedimento arbitral (Baptista, 1998). Foi dada maior institucionalidade ao Mercosul para diminuir as incertezas que potencialmente criassem conflitos (Vigevani, 1998), e parte disso se fez através da criação desse sistema, mas sem afetar a natureza intergovernamental do bloco. Dessa forma, tanto a estrutura do Mercosul quanto o seu mecanismo de solução de controvérsias não significaram a criação de órgãos supranacionais e tampouco a de um sistema jurídico permanente.

Atualmente no Mercosul, o procedimento se ampara na solução político-diplomática, já que após a primeira fase de negociação direta entre as partes a questão é submetida à CCM e posteriormente ao GMC, órgãos em que predomina a negociação política dos Estados. Ademais, o sistema em vigor não permite a formação de jurisprudência, pois as primeiras fases são soluções negociadas caso a caso, seguindo o Tribunal Arbitral a mesma lógica.

\section{CONFLITOS COMERCIAIS}

A partir do ano de 1999, o Mercosul foi marcado por diversas disputas comerciais entre Brasil e Argentina, com retaliações e ameaças recíprocas. As tensões, em alguns casos, não puderam ser solucionadas pela via diplomática, levando ao acionamento do Tribunal Arbitral, em 1999, que se pronunciou sobre três disputas diferentes. Esse órgão nunca havia sido acionado, apesar de estar previsto desde 1991. O estopim desse período de turbulências foi a desvalorização cambial brasileira, acompanhada do término do regime de adequação em $1^{\circ}$ de janeiro de 1999 , deixando às claras as reais diferenças em termos comerciais e de competitividade entre a indústria brasileira e a argentina.

Seguindo essas três negociações, pode-se ver como a atual conformação institucional do bloco contribuiu para 
criar um ambiente de incertezas na região, levando inclusive à necessidade de promover um "relançamento do Mercosul".

A primeira decisão do Tribunal Arbitral foi em relação ao dispositivo brasileiro de licenças de importação não-automáticas. $\mathrm{O}$ governo argentino e as empresas exportadoras desse país consideraram o regime de licenciamento prévio de importação adotado pelo Brasil, em outubro de 1998, uma barreira não-tarifária. A Câmara de Exportadores da República Argentina (Cera) reclamava que a liberação de uma LI (Licença de Importação) podia levar mais de 30 dias, afirmação contestada pelo governo brasileiro. O ltamaraty argumentava que sua solução poderia se dar através da negociação de um sistema harmonizado de reconhecimento dos certificados sanitário e fitossanitário do Mercosul, já que os países poderiam aceitar esse tipo de controle efetuado na origem. No entanto, não se tratava de uma discordância localizada apenas no âmbito regional, pois havia a pressão por parte de outros países, fazendo com que a questão chegasse à $\mathrm{OMC}$.

Como resultado, em maio de 1999, o Tribunal Arbitral do Mercosul, constituído em fevereiro, determinou o fim do instrumento de controle das importações brasileiras através da Licença de Importação não-automática para os países do Mercosul. O Brasil deveria cumprir as exigências até o final de 1999.

A carne suína sem osso foi o segundo caso julgado pelo Tribunal Arbitral. Esse produto expandiu sua participação no mercado argentino, fundamentando a alegação, por parte dos produtores locais, que a carne suína brasileira contava com subsídios nos preços da ração animal (milho). Inicialmente, o governo argentino privilegiou a utilização de canais estabelecidos na Secretaria de Comércio e na chancelaria, mas não descartou a possibilidade de acionar o Protocolo de Brasília.

Entre 1995 e 1998, prevaleceu um acordo firmado entre o setor de ambos os países, que se renovava automaticamente. Porém, em outubro de 1998, os produtores argentinos de suínos romperam o acordo, levando o governo a interferir diretamente na questão. Depois de acionado o Protocolo de Brasília, no dia 28 de outubro de 1999, o Tribunal Arbitral do Mercosul, em sua segunda decisão, anunciou que o Brasil poderia vender carne suína para a Argentina com base nos preços então praticados. Dessa vez, a vitória foi dos produtores brasileiros, mas apesar dessa decisão os empresários argentinos continuaram contestando o embarque de suínos para seu país e pressionaram o governo argentino para iniciar um processo antidumping. Nesse exemplo podemos verificar que, no tocante ao setor privado, há uma falta de legitimidade das instituições de solução de controvérsias do Mercosul, apesar de a decisão ter sido reconhecida pelo governo argentino.

A terceira decisão do Tribunal Arbitral foi sobre os têxteis, porque o governo argentino aplicava cotas aos tecidos de algodão exportados pelo Brasil, alegando ter havido um aumento muito expressivo do volume exportado no primeiro semestre de 1999, sendo necessário verificar suas causas. O Grupo de Acompanhamento da Conjuntura Econômica e Comercial, criado em junho de 1999 pelo CMC, ficou responsável por analisar o caso. Em novembro de 1999, o Brasil recorreu às instituições do Mercosul e também à $\mathrm{OMC}$ e, em março de 2000, o Tribunal Arbitral do Mercosul determinou que a Argentina suspendesse as salvaguardas comerciais para os produtos têxteis brasileiros por um período de 15 dias.

No entanto, o processo contra os argentinos continuou a ser analisado na $\mathrm{OMC}$ e no dia 20 de março de 2000, pela primeira vez, a OMC abriu um painel para discutir um conflito comercial entre membros do Mercosul. A Argentina decidiu, então, utilizar-se do seu direito de pedir esclarecimentos ao Tribunal Arbitral do Mercosul, tentando ganhar mais algum tempo, mas seu pedido não foi aceito.

Outros conflitos ocorreram no período analisado, mas ao se voltar a atenção para dois conflitos específicos, referentes aos setores automotivo e açucareiro, pode-se verificar como os problemas comerciais adquirem conotações políticas, afetando as relações globais entre os integrantes do Mercosul.

O açúcar foi um dos produtos mantidos como exceção ao livre-comércio no Mercosul, fazendo parte do Regime de Adequação Final à União Aduaneira. Enquanto os negociadores técnicos brasileiros apresentaram inúmeras vezes propostas de convergência tarifária externa e desgravação tarifária interna, os argentinos, pressionados pelos seus produtores de açúcar, continuaram acusando a produção brasileira de receber subsídios indiretos, impedindo que o produto fizesse parte da zona de livre-comércio.

A acusação argentina se baseou no incentivo à produção de álcool no quadro do Programa Nacional do Álcool (Proalcool), que estimularia a plantação de cana-de-açúcar no Brasil voltada para a produção de álcool, mas que produziria o açúcar como um subproduto, recebendo incentivos indiretos.

O conflito entre os produtores argentinos e brasileiros de açúcar no Mercosul e as dificuldades para a negocia- 
ção do setor ensejaram a criação, na V Reunião do GMC, entre 30 de março e $1^{\circ}$ de abril de 1992, de uma Comissão no âmbito do SGT 8 (Política Agrícola), que, com a intervenção do SGT 7 (Política Industrial e Tecnológica) e SGT 9 (Política Energética), ficou responsável por propor alternativas para formular uma política regional para o complexo sucroalcooleiro.

Como as negociações prosseguiram sem a definição de uma proposta de política regional para o setor até agosto de 1994, o CMC constituiu um Grupo Ad Hoc, encarregado oficialmente de estudar o regime de adequação do setor açucareiro e apresentar até novembro de 1995, no máximo, uma proposta de adequação do produto ao livre-comércio. Esse prazo foi prorrogado para junho de 1997 pelo GMC, seguindo a Recomendação n ${ }^{\circ}$ 1/96 do Grupo Ad Hoc do setor açucareiro, apesar da reiteração do Brasil de que uma reunião fosse realizada para definir o regime de adequação do setor o mais breve possível. Porém, o GMC declarou na XXIV Reunião, em Fortaleza, de 12 a 14 de dezembro de 1996, sua intenção de levar a questão à consideração do $\mathrm{CMC}$, após analisar o tema e concluir não haver consenso sobre política de adequação do açúcar. Nos dias 19 e 20 de maio de 1997, em reunião do GMC, o Brasil apresentou uma proposta de desgravação tarifária progressiva e automática até a implementação do livre-comércio, prevista para vigorar a partir de $1^{\circ}$ de julho de 1997 ; entretanto, a delegação argentina impôs reservas à proposta.

Como as discussões terminaram indefinidas, o governo argentino, pressionado pelos produtores de açúcar das províncias do norte do País, editou a Lei do Açúcar $n^{\circ}$ 24.822 , impondo taxas de importação no valor de $20 \%$. Imediatamente em resposta, apresentou-se um projeto de decreto legislativo pelo secretário-geral da Comissão Parlamentar Conjunta do Mercosul (CPC), Paulo Bornhausen, proibindo todas as autorizações de importação de trigo, pois "sabidamente a Argentina exporta trigo a partir de uma cultura fortemente subsidiada (art. 2)". Em seguida, a União da Agroindústria Canavieira de São Paulo (Unica) repudiou a decisão da Argentina, fazendo uma reclamação formal à CCM contra as restrições argentinas às importações de açúcar, alegando sua inconstitucionalidade. A reclamação resultou na eliminação das taxas de importação aplicadas ao açúcar brasileiro pela Argentina e na retirada do projeto de decreto legislativo apresentado pelo secretário-geral da CPC, Paulo Bornhausen.

O CMC decidiu prorrogar o mandato do Grupo Ad Hoc até 31 de dezembro de 2000, incumbindo-o de continuar as diligências para a formulação de um regime de adequação que contemple a eliminação das tarifas aduaneiras e barreiras não-tarifárias ao comércio do açúcar no bloco.

$\mathrm{Na}$ data especificada, novamente, não foi possível negociar um acordo entre as partes e o açúcar continuou sujeito às mesmas restrições comerciais vigentes. As negociações no Grupo Ad Hoc prosseguem até a atualidade, sem no entanto alcançar um consenso, uma vez que as propostas precisam invariavelmente ser encampadas pelo GMC, pois o governo argentino se encontra impossibilitado de aceitar um acordo devido às pressões dos produtores argentinos.

As negociações do setor automotriz foram realizadas no âmbito do Subgrupo de Trabalho $n^{\circ} 7$ (Política Industrial e Tecnológica), que em março de 1992 propôs a criação de uma comissão para estudar a exportação conjunta para terceiros países e apresentar as bases para um acordo setorial de autopeças. Os representantes dos governos se encarregavam do auxílio técnico e da verificação da compatibilidade com as normas ditadas pelo Tratado de Assunção, enquanto os acordos eram negociados pelo setor privado, que se encarregou efetivamente das negociações do universo tarifário, cotas, índice de nacionalização e exceções, representado, do lado argentino, pela Associação de Fábricas de Automotores (Adefa) e pela Associação Nacional de Fábricas de Veículos Automotores (Anfavea), do lado brasileiro.

Desde a assinatura do Tratado de Assunção, o comércio intrabloco nesse setor sofreu significativa elevação, principalmente entre 1990 e final de 1992. As exportações brasileiras aumentaram devido à manutenção de um câmbio subvalorizado, provocando a deterioração da balança comercial argentina. O fluxo crescente de importações atingiu particularmente os setores industriais da Argentina, inclusive o setor automotivo, o que provocou um recuo nas negociações realizadas para definir as cotas para o ano seguinte, 1993.

Em 15 de novembro de 1992, reuniram-se representantes dos governos da Argentina e do Brasil (do lado brasileiro, participaram membros dos Ministérios de Economia, do Trabalho, de Indústria, Comércio e Turismo e, posteriormente, do Ministério de Desenvolvimento), conjuntamente com representantes da Adefa e Anfavea, para elaborar uma carta de intenções que fixou as cotas de importação em pouco mais de 40 mil veículos e um índice de nacionalização de $70 \%$ (peças originárias dos países membros do Mercosul) para usufruir da tarifa zero.

A ratificação e a entrada em vigência desse acordo foram postergadas porque a Argentina não conseguiu cumprir a cota 
de exportações para o Brasil a que tinha direito. As negociações prosseguiram até março de 1993, quando se celebrou o Anexo V ao Protocolo $\mathrm{n}^{\circ} 21$, vigente a partir do dia 31 do mesmo mês, fixando as cotas para $1993 \mathrm{em}$ pouco mais de 20 mil veículos (mantendo inalterado o índice de nacionalização). O Anexo V marca uma reorientação na política externa brasileira, que passou a privilegiar o aspecto político da integração, pois não só estabelecia uma cota inferior para o ano de 1993 em relação a 1992, para proteger a indústria automotiva argentina, como prorrogou para 31 de dezembro de 1993 o prazo para completar o restante da cota de exportações não cumprida pela Argentina em 1992, além da cota normal para o ano. É significativo o fato de que o Anexo $\mathrm{V}$ foi inteiramente elaborado pelos representantes de governo, e posteriormente submetido à apreciação dos representantes privados, que pouco puderam fazer para alterar o acordo, pois as negociações e a tomada de decisões para essas questões do setor se efetuaram inteiramente no plano do Conselho do Mercado Comum.

A declaração do embaixador Rubens A. Barbosa, exsubsecretário-geral de Integração, Assuntos Econômicos e de Comércio Exterior do Itamaraty, referente às medidas adotadas pelo Brasil para elevar as importações argentinas, mostra esta posição de forma clara: "Do ponto de vista do Mercosul, e diante dos desequilíbrios da balança comercial argentina, as medidas foram as menos traumáticas possíveis" (Gazeta Mercantil, 1992).

Em 1994, com a aproximação do fim do período de transição, as negociações se tornavam mais prementes. A Anfavea continuava a pressionar o governo brasileiro a aumentar as cotas de exportação e estabelecer rapidamente um regime comum para o setor. No entanto, a Decisão 29/ 94 do CMC, contemplando uma proposta apresentada pelo setor privado uruguaio, evidenciou as dificuldades dos governos em atender simultaneamente às reivindicações dos setores privados nacionais e aos objetivos da integração, criando um Comitê Técnico Ad Hoc na futura Comissão de Comércio do Mercosul (CCM), que se encarregaria da elaboração de uma proposta de Regime Automotriz Comum para o bloco.

O Comitê Técnico Ad Hoc deveria apresentar para a aprovação da CCM uma proposta completa do Regime Automotriz Comum até 31 de dezembro de 1997, que contivesse os seguintes elementos: liberalização do comércio intrazona para os produtos do setor automotriz; uma tarifa externa comum; e a ausência de incentivos nacionais que distorcessem a competitividade na região. O regime comum deveria entrar em vigor a partir de $1^{\circ}$ de janeiro de 2000 .
Diante das dificuldades de se obter uma proposta consensual no âmbito do Comitê Técnico, o CMC decidiu postergar o prazo final para a apresentação da proposta do Comitê para 30 de abril de 1998. Esse prazo foi sucessivamente prorrogado até o fim de 1999, quando definiuse o regime de transição que vigoraria entre 2001 e 2003, até atingir o livre-comércio em 2004.

No final do ano de 1998, foi estabelecido que o regime automotivo definitivo do Mercosul contemplaria o livre-comércio interno, com Tarifa Externa Comum (TEC) de 35\% para veículos e entre $16 \%$ e $18 \%$ para autopeças. Porém, seria por meio de um regime de transição a vigorar entre $1^{\circ} \mathrm{de}$ janeiro de 2000 e 31 de dezembro de 2003 . Somente em $1^{\circ}$ de janeiro de 2004 seria atingido o livre-comércio interno.

As divergências se tornaram mais evidentes a partir da desvalorização do real, focando-se nas negociações quanto ao índice de nacionalização. Ao mesmo tempo, a Argentina passou a dificultar a entrada de veículos obrigando os importadores a apresentarem uma declaração detalhada da mercadoria. Além disso, solicitou à OMC a prorrogação do regime automotivo nacional, suscitando ameaças do Brasil de submeter os veículos importados da Argentina à TEC. No final do prazo, quando deveriam ser definidas as regras do setor que iriam vigorar a partir de 2000 , estabeleceu-se um acordo provisório até 29 de fevereiro, em virtude, principalmente, das divergências sobre o índice de nacionalização de peças, enquanto as negociações prosseguiam. As negociações ainda estão ocorrendo e não se definiu um regime de convergência tarifária que possa alcançar o livre-comércio no futuro.

\section{ALGUMAS CONCLUSÕES}

Ao se analisar o período que vai do início de 1998 até os dias que antecedem o retorno do Ministro Domingo Cavallo ao governo argentino, pode-se notar um esgotamento na forma de avançar nas negociações do Mercosul, que até então privilegiava os assuntos mais fáceis de resolver, deixando os temas mais críticos para depois. Ao mesmo tempo, permite questionar a viabilidade da estratégia da via diplomática de solução de conflitos. Nesse sentido, o setor burocrático-estatal ainda se mostra como a principal influência que permeia as negociações. Na prática, essa influência se traduz na opção da via diplomática em detrimento do aprofundamento dos mecanismos institucionalizados.

Se, por um lado, está o problema estrutural dos setores econômicos sensíveis, de outro, essa opção mostrou-se 
pouco eficiente e prejudicial ao fortalecimento de mecanismos de solução de controvérsias, o que poderia ajudar na percepção empresarial de que os órgãos do Mercosul seriam mais adequados para o encaminhamento das divergências do que a pressão direta aos governos nacionais ou o apelo aos mecanismos da OMC.

Essa forma de negociação faz com que fatores não relacionados diretamente ao processo de solução de conflitos sejam agregados, como pode-se verificar no segundo semestre de 1999, quando ficou clara a disposição do Itamaraty em atrasar as negociações com a Argentina até que o novo governo fosse empossado.

Nesse exemplo, setores econômicos importantes precisaram adequar suas prioridades comerciais ao calendário eleitoral de um Estado-parte. Esse tipo de acontecimento faz com que os agentes econômicos percebam a situação da integração como carente de credibilidade e previsibilidade, elemento que deveria ser privilegiado num processo de integração regional.

Paraguai e Uruguai, juntamente com a Argentina, muito em função da sua situação socioeconômica interna, começaram a perceber a estagnação dessa forma de conduzir as negociações e partiram para a tentativa de colocar na agenda de discussões o aprimoramento dos instrumentos jurídicos comuns. Mesmo no caso do Brasil, país mais reticente quanto à criação de instrumentos que possam avançar além do âmbito intergovernamental, já há sinais de mudança de postura. Como exemplo temos o Ministro Lampréia (1999) que discutiu a possível necessidade de fortalecimento de mecanismos institucionais de mediação, como a ampliação do papel dos tribunais arbitrais, de forma que os conflitos comerciais e outros tenham instâncias adequadas de solução, sem necessidade de afetar o conjunto do sistema integracionista, inclusive mobilizando a própria Presidência da República em temas ordinários.

Outra declaração que reforça a necessidade de mudanças mais abrangentes foi feita pelo Ministro Celso Lafer (2001): “(...) Para dinamizar o bloco, há necessidade de maior integração. Temos de dar passos firmes na direção do Mercado Comum, da integração das cadeias produtivas, da integração das infra-estruturas físicas, além de aperfeiçoar os aspectos institucionais, buscando aprimorar o mecanismo de solução de controvérsias, coordenar mecanismos de defesa comercial extrazona e a eliminação de medidas intrazona, instalando, em seu lugar, um sistema comum de defesa da concorrência. Além disso, devemos trabalhar por políticas comuns em áreas tais como zoofitossanitárias e certificação, entre outras. Para tanto, devemos obedecer a uma agenda, tal como já fizemos no passado, quando estabelecemos o cronograma em Las Leñas (...)”.

A declaração do Presidente Fernando Henrique Cardoso, ${ }^{4}$ embora ainda não possa ser vista como reflexo de uma ação determinada por parte do governo brasileiro para mudar a estrutura institucional do Mercosul, mostra que os condutores da política de integração estão percebendo o esgotamento do atual sistema de resolução de conflitos e de encaminhamento das negociações, admitindo até a possibilidade de adoção da supranacionalidade.

Entendemos que o Mercosul encontra-se numa fase em que a interdependência entre as questões regionais e as domésticas já é bastante importante e tende a se aprofundar. O processo de integração tem gradativamente demandado mais estabilidade, para que fatores domésticos possam ser processados de forma que não constituam elementos de interferência prejudicial à evolução das negociações em torno de um futuro compartilhado. As reiteradas vezes que os governos argentino e brasileiro utilizaram ameaças ou retaliações permitem confirmar a tendência de que a aplicação de medidas restritivas em um setor faz com que esta contagie outro, formando um quadro no qual evidenciam-se diferenças e não os aspectos comuns, e as divergências comerciais tendem a assumir uma conotação mais política e menos técnica, fazendo com que as disputas passem do setor empresarial para o setor governamental.

A evolução da estrutura institucional no Mercosul, como descrita neste artigo, dificulta a participação de forma mais direta dos setores não-governamentais, o mesmo acontecendo com os mecanismos de solução de controvérsia adotados. Essa dificuldade tende a fazer com que as negociações do setor privado se realizem fora dos canais próprios da integração, dependendo continuamente do envolvimento dos governos nos assuntos negociados. As crises enfrentadas nos últimos anos podem ser o início de um processo de transformação organizacional, tanto das instituições do Mercosul quanto dos governos envolvidos e dos setores responsáveis pela tomada de decisões em política externa, em que a agenda nacional poderá mesclar-se mais com as necessidades regionais, e vice-versa.

\section{NOTAS}

Este artigo é fruto da pesquisa "Gestão Pública Estratégica de Governos Subnacionais Frente aos Processos de Inserção Internacional e Integração Latino-americana", que está sendo realizada pelo Cedec, Fundap e PUC-SP, contando com o apoio da Fapesp. 
1. Discurso do Senhor Presidente da República, Fernando Henrique Cardoso, na Reunião de Cúpula do Mercosul, por ocasião da Reunião do Conselho do Mercado Comum, Assunção, 22 de junho de 2001.

2. Artigo 3 do Tratado de Assunção e Anexo III.

3. Realizada em 17 de dezembro de 1991.

4. “(...) Um espaço cuja vocação vai além do comércio: a vocação de integração profunda no plano econômico, inclusive monetário, e de crescente unidade no plano político, unidade que, no devido momento, encontrará expressão em instituições de caráter supranacional (...)". Trecho reproduzido do discurso proferido na Reunião de Cúpula do Mercosul, por ocasião da Reunião do Conselho do Mercado Comum (2001).

\section{REFERÊNCIAS BIBLIOGRÁFICAS}

ALMEIDA, P.R. Mercosul: fundamentos e perspectivas. São Paulo, LTr, 1998.

ALMEIDA, P.R. O Mercosul no contexto regional e internacional. São Paulo, Aduaneiras, 1993.

ARCHAR, D. et alii. Las elites argentinas y brasileñas frente al Mercosur. Buenos Aires, BID/Intal, 1994.

BAPTISTA, L.O. O Mercosul, suas instituições e ordenamento jurídico. São Paulo, LTr, 1998.

CARDOSO, F.H. Discurso proferido na reunião de cúpula do Mercosul, por ocasião da reunião do Conselho do Mercado Comum. Assunção, 22 de junho de 2001.

CHARLIN, R.B. "Dimensión jurídica e instrumental de la integración latinoamericana". Contribuciones. Buenos Aires, Ciedla/Konrad Adenauer, ano X, v.38, n.2, abr.-jun. 1993.

GAZETA MERCANTIL. "Medidas foram as menos traumáticas". São Paulo, 30/10/1992.

FUNCEX. "Um Balanço do Mercosul". Revista Brasileira de Comércio Exterior. Rio de Janeiro, n.41, out.-dez. 1994.
HIRST, M. “A dimensão política do Mercosul: atores, politização e ideologia". Texto original apresentado no Seminário Processos de Integração Regional e as Respostas da Sociedade: Argentina, Brasil, México e Venezuela. São Paulo, IEA/USP, 7 e 8 de agosto de 1995.

LAFER, C. "El Mercosur está vivo. Y va en el rumbo que le dan sus socios". Clarín. Buenos Aires, 17 jun. 2001.

LAMPRÉIA, L.F. Intervenção no Grupo de Análise de Conjuntura (Gacint) do IEA/USP. São Paulo, 4 de outubro de 1999.

MARIANO, K.L.P. A atuação da Comissão Parlamentar Conjunta e do Subgrupo de Trabalho 10 no Mercosul. Tese de Doutorado. Campinas, Instituto de Filosofia e Ciências Humanas/Unicamp, 2001.

MARIANO, M.P. A estrutura institucional do Mercosul. São Paulo, Aduaneiras, 2000.

MENDES, R.G. Resolução de controvérsias no Mercosul: os interesses subnacionais. São Paulo, Centro de Estudos de Cultura Contemporânea, Cadernos Cedec n.69, 2001.

NYE, J.S. "Comparing common markets: a revised neofunctionalist model". In: KRATOCHWIL, F. e MANSFIELD, E. (orgs.) International Organization. A Reader. Nova York, Harper Collins College Publishers, 1994.

OTEIZA, E. "Mercosur: crítica del sistema arbitral del Protocolo de Brasília". Revista Uruguaya de Derecho Procesal. Montevidéu, 1992.

TOMASSINI, L. Relaciones internacionales: teoria y practica. PNUD/ Cepal - Documento de Trabajo n.2, 1988.

VIGEVANI, T. Mercosul: impactos para trabalhadores e sindicatos. São Paulo, Ed. LTr, 1998.

Tullo Vigevani: Cientista Politico, Professor da Unesp e Pesquisador Cedec (vigevanit@uol.com.br).

Marcelo Passini Mariano: Cientista Político, Pesquisador Cedec (marcelo-mariano@uol.com.br).

Ricardo Glöe Mendes: Pesquisador Cedec (ricardgm@terra.com.br). 